\title{
Characterisation of an emerging rickettsia-like organism in Tasmanian farmed Atlantic salmon Salmo salar
}

\author{
Serge Corbeil*, Alex D. Hyatt, Mark St. J. Crane \\ AAHL Fish Diseases Laboratory, Australian Animal Health Laboratory, CSIRO Livestock Industries, Private Bag 24, \\ Geelong, Victoria 3220, Australia
}

\begin{abstract}
A rickettsia-like organism (RLO) was observed in farmed Atlantic salmon Salmo salar located in south-east Tasmania, Australia. Several assays such as immunoperoxidase, immunoelectron microscopy, polymerase chain reaction and nucleic acid sequencing, as well as phylogenetic analysis of rDNA sequences, were performed on infected fish tissues. Immunohistochemistry results suggested the presence of related antigenic determinants between the Tasmanian RLO and the type strain LF-89 of Piscirickettsia salmonis. However, sequence alignment demonstrated that the Tasmanian RLO contains a $19 \mathrm{bp}$ deletion at the 3 '-end of the internal transcribed spacer region of the rDNA operon, indicating a genetic divergence from P. salmonis isolates, which are exotic to Australia.
\end{abstract}

KEY WORDS: Rickettsia-like organism $\cdot$ rDNA sequences $\cdot$ Differential antigenicity $\cdot$ Piscirickettsia salmonis $\cdot$ Atlantic salmon

\section{INTRODUCTION}

Piscirickettsia salmonis, an obligate intracellular bacterial pathogen of salmonids, was identified as the aetiological agent of the disease known as piscirickettsiosis (Fryer et al. 1990, Fryer \& Mauel 1997). P. salmonis was classified as a member of the Proteobacteria gamma subdivision based on 16S rRNA sequence (Fryer et al. 1992). Several salmonid species, including coho salmon Oncorhynchus kisutch and Atlantic salmon Salmo salar, are susceptible to infection. Outbreaks of the disease in farmed fish can cause substantial mortalities, leading to significant financial loss (Bravo \& Campos 1989). To date, piscirickettsiosis has been identified in Chile (Bravo \& Campos 1989), Ireland (Rodger \& Drinan 1993), Norway (Olsen et al. 1997), Scotland (Grant et al. 1996, Birrell et al. 2003), and both the east (Jones et al. 1998) and west coasts of Canada (Evelyn 1992).

The recent detection of a rickettsia-like organism (RLO) through Giemsa staining and polymerase chain reaction (PCR) amplification from tissues taken from farmed Atlantic salmon in Tasmania, Australia (Handlinger \& Ellard pers. comm.) has identified a need to further characterise this RLO at the antigenic and molecular level in order to establish its relatedness to Piscirickettsia salmonis isolates exotic to Australia.

\section{MATERIALS AND METHODS}

Piscirickettsia salmonis isolates. DNA from the Chilean (LF-89), Canadian (ATL-4-91) and Norwegian (NOR-92) reference strains of $P$. salmonis was obtained from cell culture supernatants as described previously (Corbeil et al. 2003) and used as positive controls for PCR amplification. The nucleotide sequences for the 16S rRNA gene or 16S-23S internal transcribed spacer region of $P$. salmonis LF-89 (GenBank accession numbers U36941 and U36943), NOR-92 (GenBank accession numbers U36942 and U36946), ATL-4-91 (GenBank accession numbers U36915 and U36945), SLGO-94 (Chile) (GenBank accession number U55015), EM-90 (Chile) (GenBank accession numbers 
U36940 and U36944), and C1-95 (Chile) (GenBank accession number U62103) were aligned and compared using the Clustal W algorithm (Thompson et al. 1994, BioManager from the Australian National Genomic Information Service, http://www.angis. org.au).

Tasmanian RLO isolates and DNA extraction. The RLO isolates used for genomic characterisation were harvested from 2 yr old moribund Atlantic salmon farmed in 2 different locations in the Huon Estuary D'Entrecasteaux Channel, South East Tasmania, over a 2 yr period (2001 to 2002). Liver, kidney and brain tissues from 1 fish in the first year and 2 fish from the following year were processed in order to compare the rRNA sequences of the RLO isolates. DNA was extracted from formalin-fixed and fresh salmon tissues (approximately $20 \mathrm{mg}$ total tissue) by rinsing them in phosphate-buffered saline (PBS), followed by a digestion with Proteinase $\mathrm{K}$ and DNA elution using a QiaAmp DNA minikit (Qiagen) according to the manufacturer's instructions. DNA was eluted and resuspended in a final volume of $50 \mu \mathrm{l}$ of sterile deionised water.

PCR amplification of the Tasmanian RLO rDNA genes. Partial regions of the $16 \mathrm{~S}$ gene of the rDNA operon of the Tasmanian RLO were amplified following a method described by Mauel et al. (1996) using the PS2S and PS2AS primer set. The internal transcribed spacer (ITS) of the rDNA operon was amplified using methods described by Marshall et al. (1998), using the ITS1 and RTS4 primer set, and Casanova et al. (2001) using the universal primers L1 and G1 with the following modifications: the mixture was denatured at $94^{\circ} \mathrm{C}$ for 2 min and amplified by 35 cycles at $94^{\circ} \mathrm{C}$ for $30 \mathrm{~s}, 55^{\circ} \mathrm{C}$ for $30 \mathrm{~s}$, and $72^{\circ} \mathrm{C}$ for $40 \mathrm{~s}$. The resulting amplicons were resolved by electrophoresis in $2 \%$ agarose gels in $1 \mathrm{X}$ TAE (Tris-acetate $0.04 \mathrm{M}$, EDTA $0.001 \mathrm{M}$ ) buffer. Gels were stained with ethidium bromide $\left(0.5 \mu \mathrm{g} \mathrm{ml}^{-1}\right)$.

Sequence determination. The 16S rRNA partial gene and the ITS region sequences (GenBank accession numbers AY578984 and AY578985, respectively) were determined by direct sequencing of the PCR product. Sequencing was carried out using an ABI PRISM Ready Reaction Big Dye ${ }^{\circledR}$ Termination Cycle Sequencing Kit (Perkin-Elmer) and an ABI PRISM model 377XL DNA sequencer (Sequencing Analysis 3.4.1 Software, Version 2.6 [Perkin-Elmer]).

Phylogenetic analysis. Each Tasmanian RLO sequence was confirmed from 3 separate amplicons, each of which was obtained from different amplification reactions. The amplicons were sequenced in both forward and reverse directions. The Tasmanian RLO and Piscirickettsia salmonis sequences were aligned and phylogenetic trees were constructed from the sequence data using the DNA Distance + Neighbor programs in PHYLIP Phylogeny Inference Package Version 3.2 (Felsenstein 1989, Biomanager, Australian National Genomic Information Service). For comparisons between the Tasmanian RLO and the P. salmonis isolates using the partial 16S rDNA gene and ITS region, 445 and 265 bp sequences were utilised, respectively, bootstrapped 100 times.

In vivo amplification of the Tasmanian RLO for cell culture. Three tissue samples originating from 1 Tasmanian farmed Atlantic salmon showing gross signs of RLO infection and testing positive for RLO by PCR were homogenised $(10 \% \mathrm{w} / \mathrm{v})$ in PBS without $\mathrm{Ca}^{2+}$ or $\mathrm{Mg}^{2+}$ ions (PBS- $\mathrm{A}_{i} \mathrm{pH}$ 7.4) using a mortar and pestle. Aliquots $(200 \mu \mathrm{l})$ of tissue supernatants were injected into $30 \mathrm{~g}$ Atlantic salmon (obtained from Snob's Creek Fish Hatchery, Victoria, where the presence of RLO has never been observed). At $12 \mathrm{~d}$ post-inoculation, tissues from moribund fish as well as negative control fish were sampled and processed for cell culture isolation and laboratory examination.

Cell culture isolation. Liver and kidney tissues were aseptically removed from 11 experimental moribund fish ( $30 \mathrm{~g}$ in weight) and were individually homogenised in $5 \mathrm{ml}$ of antibiotic-free Eagle's Minimum Essential Medium (EMEM, Gibco) containing $10 \%(\mathrm{v} / \mathrm{v})$ fetal bovine serum (FBS, Gibco). Aliquots (100 $\mathrm{\mu l}$ ) of $10^{-1}$ and $10^{-3}$ dilutions of the homogenates were used to inoculate duplicate $25 \mathrm{~cm}^{2}$ monolayer cultures of 3 fish cell lines (chinook salmon embryo, CHSE-214; epithelioma papulosum cyprini, EPC; rainbow trout gonad, RTG-2). The monolayer cultures were incubated at $15^{\circ} \mathrm{C}$ for $30 \mathrm{~d}$ and monitored for cytopathic effects. Cell culture isolation was also attempted from 9 Tasmanian moribund farmed Atlantic salmon ( 2 yr of age) over a 4 mo period.

Immunoperoxidase assay. Formalin-fixed tissues were dehydrated and processed through to paraffin blocks using standard procedures. For each experiment, sections from negative control tissues from uninfected Atlantic salmon originating from Victoria, Australia, positive control tissues from coho salmon experimentally infected with the LF-89 isolate of Piscirickettsia salmonis in the USA and liver tissues from 6 moribund Tasmanian Atlantic salmon ( 2 yr old) were treated as follows. Following deparaffinisation, the sections were washed with PBS-A and then incubated for $1 \mathrm{~h}$ at $37^{\circ} \mathrm{C}$ with a polyclonal sheep anti-P. salmonis (LF-89) (Microtek) or normal sheep serum at a dilution of $1: 100$ in $1 \%(\mathrm{w} / \mathrm{v})$ skim milk in PBS-A. After washing in PBS-A, the sections were incubated for $1 \mathrm{~h}$ at $37^{\circ} \mathrm{C}$ with a peroxidase-conjugated donkey anti-sheep IgG (Amersham) diluted 1:200 in 0.1\% (w/v) skim milk in PBS-A. Following a further wash in PBS-A, the sections were incubated with freshly prepared substrate 
solution: $2 \mathrm{mg} 3$ amino-9-ethyl carboxyzole (AEC) (Sigma), $200 \mu \mathrm{l}$ dimethylformamide (VWR), $10 \mathrm{ml}$ $0.05 \mathrm{M}$ acetate buffer $\mathrm{pH} 5.0,5 \mu \mathrm{l} 30 \%$ (v/v) hydrogen peroxide (VWR) for $20 \mathrm{~min}$ at room temperature. The sections were rinsed in tap water, counterstained with Mayer's haematoxylin and mounted in GelTol (Immunon) for examination by light microscopy.

Preparation of ultrathin samples for electron microscopy. Sections of formalin fixed liver tissues from 1 Atlantic salmon (30 g in weight), originating from an experimental infection, embedded in paraffin and correlating to areas that were positive by immunoperoxidase assay, were cut from the blocks and processed as follows. Excised portions of the block were deparaffinised, washed in PBS-A prior to fixation in $2.5 \%$ (v/v) glutaraldehyde (90 min) in $0.1 \mathrm{M}$ cacodylate buffer $(\mathrm{pH} 7.2)$, washed $(3 \times 20 \mathrm{~min})$ in the same buffer, post-fixed in $1 \%(\mathrm{w} / \mathrm{v})$ osmium tetroxide $(1 \mathrm{~h})$, rinsed $(3 \times 5 \mathrm{~min})$ in water and dehydrated through a graded series of ethanol (20 min each). Specimens were then infiltrated and embedded in Spurr's epoxy resin or LR White Resin. Sections embedded in Spurr's resin were used for ultrastructural examination and those embedded in LR White Resin were used for immunoelectron microscopic examination.

Immunoelectron microscopy. Ultrathin sections were washed in PBS (3 min), incubated in PBS for a further $10 \mathrm{~min}$ and then placed in humid incubation chambers (Hyatt 1989, 1991) and incubated with the Piscirickettsia salmonis LF-89 isolate antiserum (diluted 1:200 in PBS) for $2 \mathrm{~h}$ at room temperature (22 to $\left.24^{\circ} \mathrm{C}\right)$. Sections were then washed with PBS $(6 \times$ $3 \mathrm{~min}$ ) and incubated with protein A-gold (10 nm particles) (diluted 1:100) at room temperature $\left(22\right.$ to $\left.24^{\circ} \mathrm{C}\right)$. Sections were subsequently washed with PBS, postfixed with $2.5 \%$ cacodylate-buffered glutaraldehyde (5 min), rinsed in water $(3 \times 3 \mathrm{~min})$ and stained with lead citrate and uranyl acetate. All specimens were examined at either 75 or $100 \mathrm{kV}$ with a Hitachi $\mathrm{H7} 7000$ scanning transmission electron microscope, calibrated with a 2160 lines $\mathrm{mm}^{-1}$ grating replica.

\section{RESULTS}

\section{Cell culture}

In contrast to Piscirickettsia salmonis reference isolates LF-89, ATL-4-91 and NOR-92 obtained from other laboratories, inoculation of cell cultures with tissue homogenates from Tasmanian RLO infected moribund fish (either naturally infected farmed fish or experimentally infected fish) did not result in growth of the Tasmanian RLO. Inoculated cells remained healthy for the duration of the experiment.

\section{Immunohistochemistry}

The use of the sheep anti-Piscirickettsia salmonis antisera resulted in bright red staining for the homologous positive control tissues (Fig. 1) whereas the Tasmanian RLO infected tissue reacted only moderately (Fig. 2). RLO infected tissue stained with a nonimmune sheep serum did not show any significant staining (Fig. 3).

\section{Electron microscopy}

Examination of ultrathin sections of RLO infected liver tissue showed coccoid pleomorphic organisms

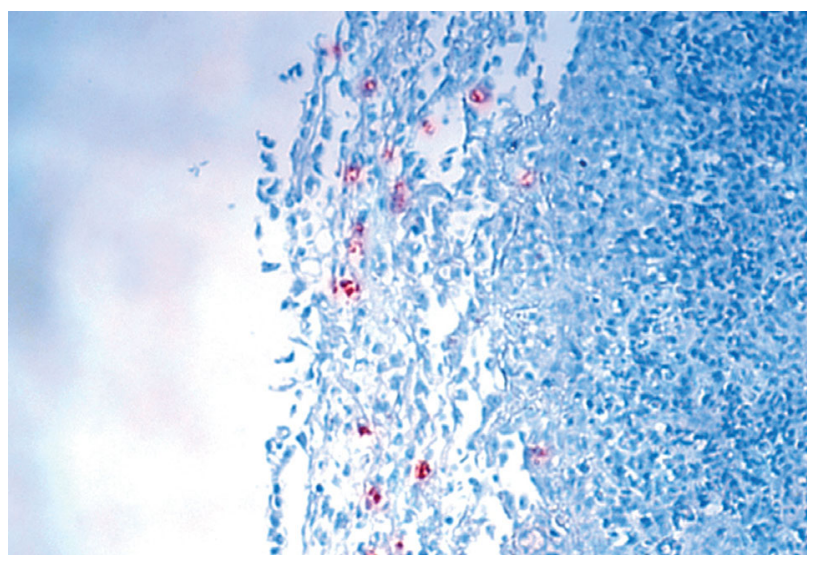

Fig. 1. Salmo salar. Immunohistochemistry of Piscirickettsia salmonis (LF-89 isolate) infected coho salmon liver, using sheep anti-LF-89 Piscirickettsia salmonis polyclonal antibodies. Salmon tissue originates from an experimental infection. Magnification $\times 200$

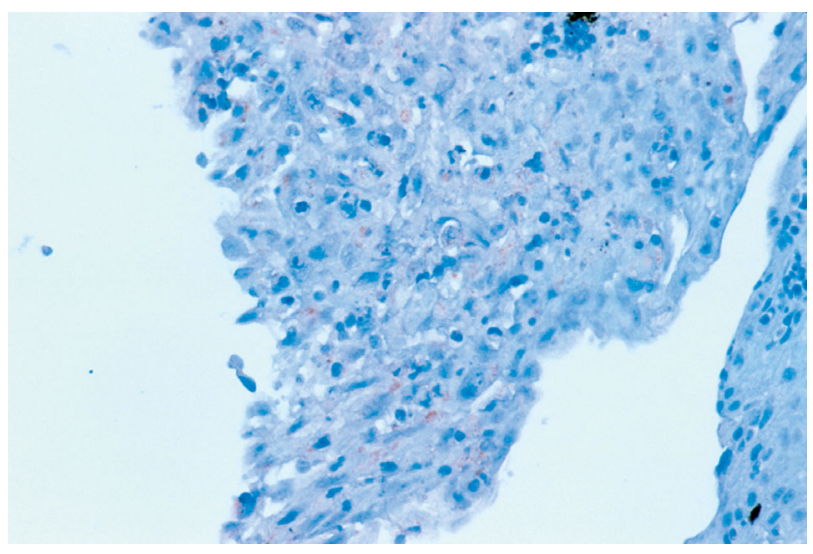

Fig. 2. Salmo salar. Immunohistochemistry of Tasmanian rickettsia-like organism infected Atlantic salmon liver, using sheep anti-LF-89 Piscirickettsia salmonis polyclonal antibodies. Salmon tissue originates from an experimental infection. Magnification $\times 400$ 


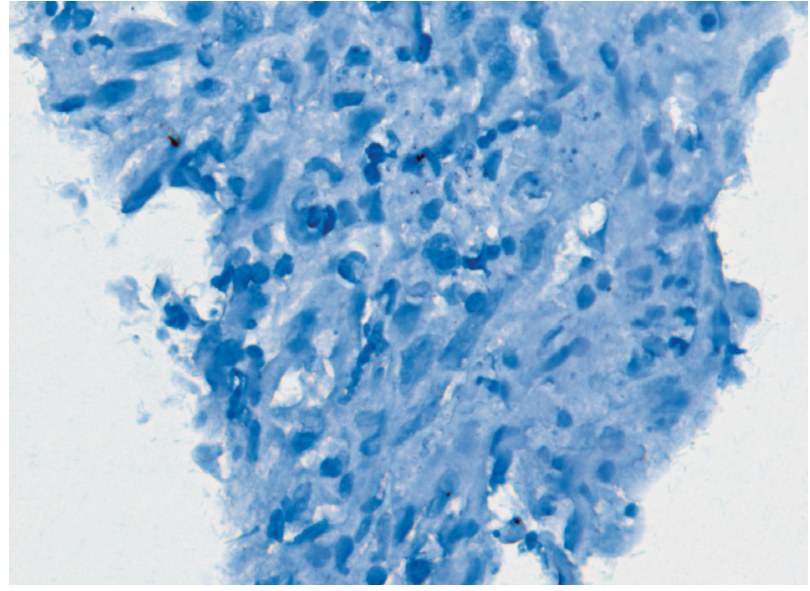

Fig. 3. Salmo salar. Immunohistochemistry of Tasmanian rickettsia-like organism infected Atlantic salmon liver, using non-immune sheep polyclonal antibodies. Salmon tissue originates from an experimental infection. Magnification $\times 800$

possessing nucleoid regions containing electron-dense central areas, as well as an undulating outer cell membrane and second inner membrane (Fig. 4 \& 5). The organisms varied in diameter from approximately 0.6 to $1 \mu \mathrm{m}$ (Fig. 4). Examination of sections incubated with Piscirickettsia salmonis LF-89 antiserum and protein A-gold revealed the presence of weak but specific gold labelling. Labelling was restricted to the coccoid organisms. No labelling was observed outside of these areas (Fig. 5) or in uninfected tissue (Fig. 6).

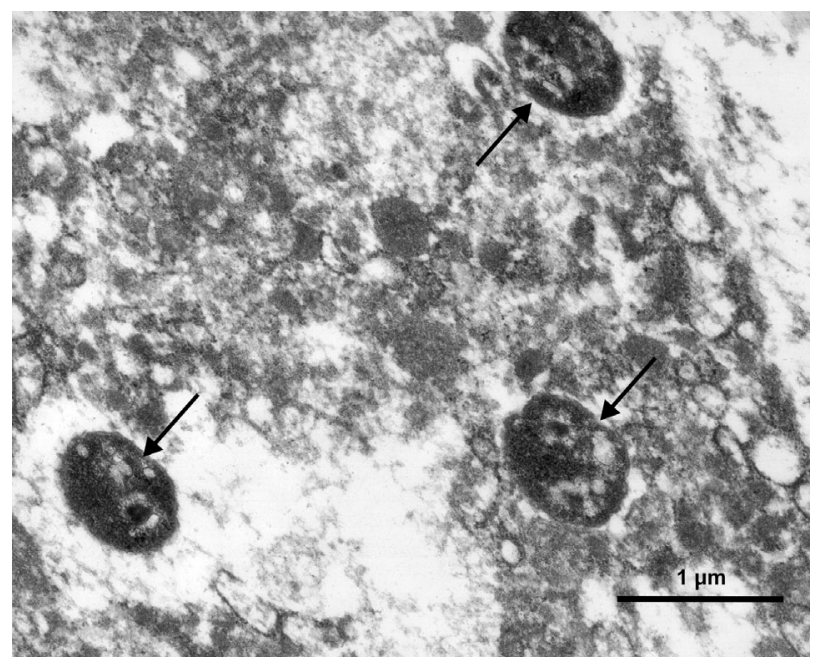

Fig. 4. Salmo salar. Electron photomicrograph of Atlantic salmon liver infected with the Tasmanian rickettsia-like organism (arrows). Salmon tissue originates from an experimental infection

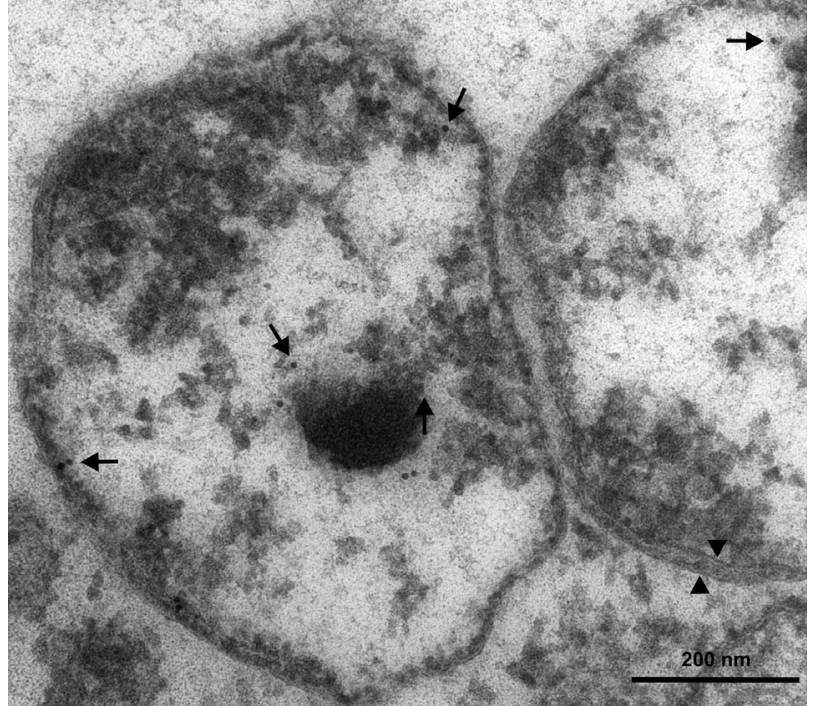

Fig. 5. Salmo salar. Immunoelectron photomicrograph of Atlantic salmon liver infected with the Tasmanian rickettsialike organism. Piscirickettsia salmonis specific polyclonal antibodies gold beads (arrows). Bi-layer undulating membranes (arrowheads). Salmon tissue originates from an experimental infection

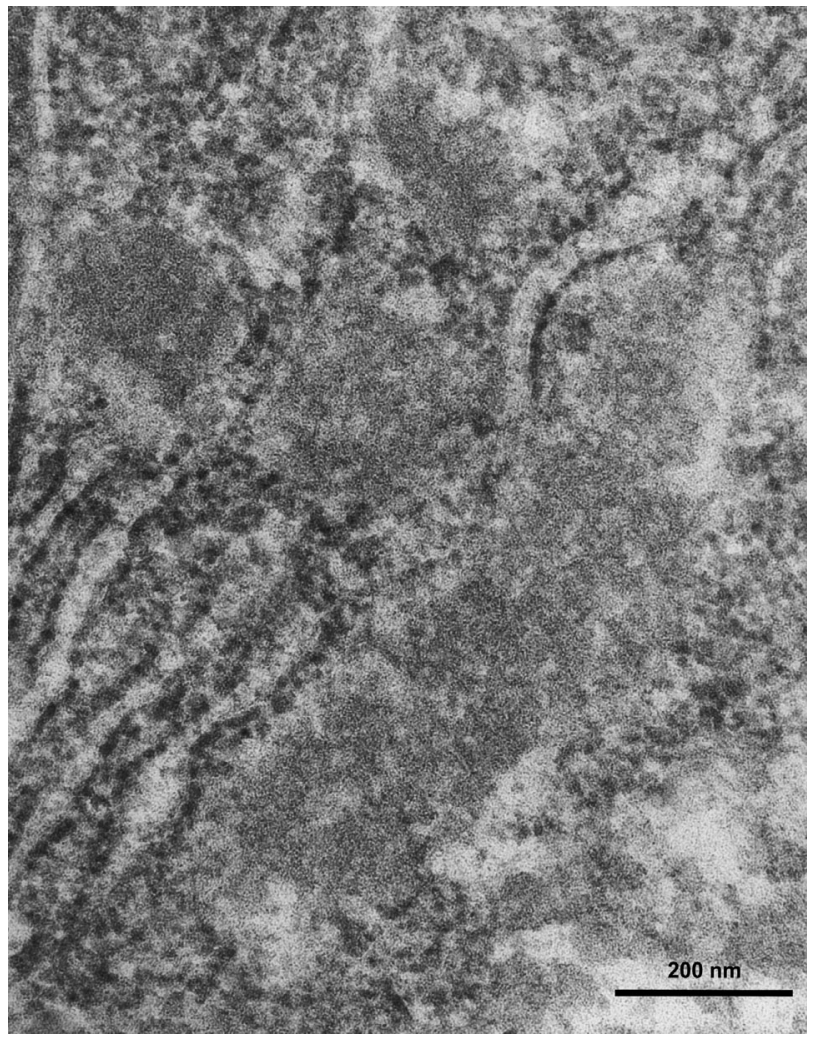

Fig. 6. Salmo salar. Electron photomicrograph of uninfected Atlantic salmon liver stained with the Piscirickettsia salmonis specific polyclonal antiserum and gold beads. Salmon tissue originates from an uninfected control group of an experimental infection trial 


\section{PCR amplification and sequencing analysis}

The primer sets PS2S-PS2AS (16S region) and ITS1-ITS-4 (ITS region) were used to amplify the Tasmanian RLO DNA. DNA from Piscirickettsia salmonis isolates LF-89, NOR-92, ATL-4-91 were used as positive controls. Primers specific for the $16 \mathrm{~S}$ region produced amplicons of expected size (Mauel et al. 1996) for all samples tested (results not shown). The second PCR amplification using the ITS specific primers produced amplicons of the expected size (Marshall et al. 1998) for the $P$. salmonis isolates and an amplicon of smaller size for the Tasmanian RLO (result not shown). Sequencing revealed a deletion of 19 consecutive base pairs located at the $3^{\prime}$-end of the ITS sequence (Fig. 7). Two amplicons were obtained from the PCR amplification using the universal primers L1 and G1, performed on the LF89 isolate of $P$. salmonis as well as on the Tasmanian RLO. Amplicon sizes were slightly different between the isolates (result not shown). Sequencing of the RLO PCR products showed that the larger amplicon was identical to the smaller one at the termini, but the sequence was interrupted by an insert of around $300 \mathrm{bp}$ containing tRNA-Ala and tRNA-Ile as previously described by Casanova et al. (2001). The 2 tRNA sequences are identical between the RLO and the LF-89 and EM-90 isolates of $P$. salmonis, with the exception of a cytidine instead of a thymidine in position 61 of the RLO tRNA-Ala (results not shown).

\section{Phylogenetic analysis}

The phylogenetic analyses were performed using 445 bases from the $16 \mathrm{~S}$ region and 265 bases from the ITS region including insertions and deletions. When the analysis was conducted using these 2 sets of sequences, both trees suggested that the EM-90 isolate of Piscirickettsia salmonis is most closely related to the Tasmanian RLO (Fig. 8) of the isolates included in this study.

\section{DISCUSSION}

Previous studies on this emerging disease of farmed Atlantic salmon in Tasmania concluded that a RLO was the aetiological agent (Handlinger \& Ellard pers. comm.). In this study, electron microscopic observations of the Tasmanian RLO support the initial histological identification of a RLO in the fish tissues (Handlinger \& Ellard pers. comm.). The weak immunohistochemical staining obtained with the Tasmanian RLO infected tissues suggests antigenic similarity with the LF-89 isolate of Piscirickettsia salmonis. The immunogold staining of the RLO supports the immunohistochemical staining result and also suggests that the P. salmonis antiserum (directed against the LF-89 strain) cross-reacts with the Tasmanian RLO, hence suggesting the presence of at least some shared anti-

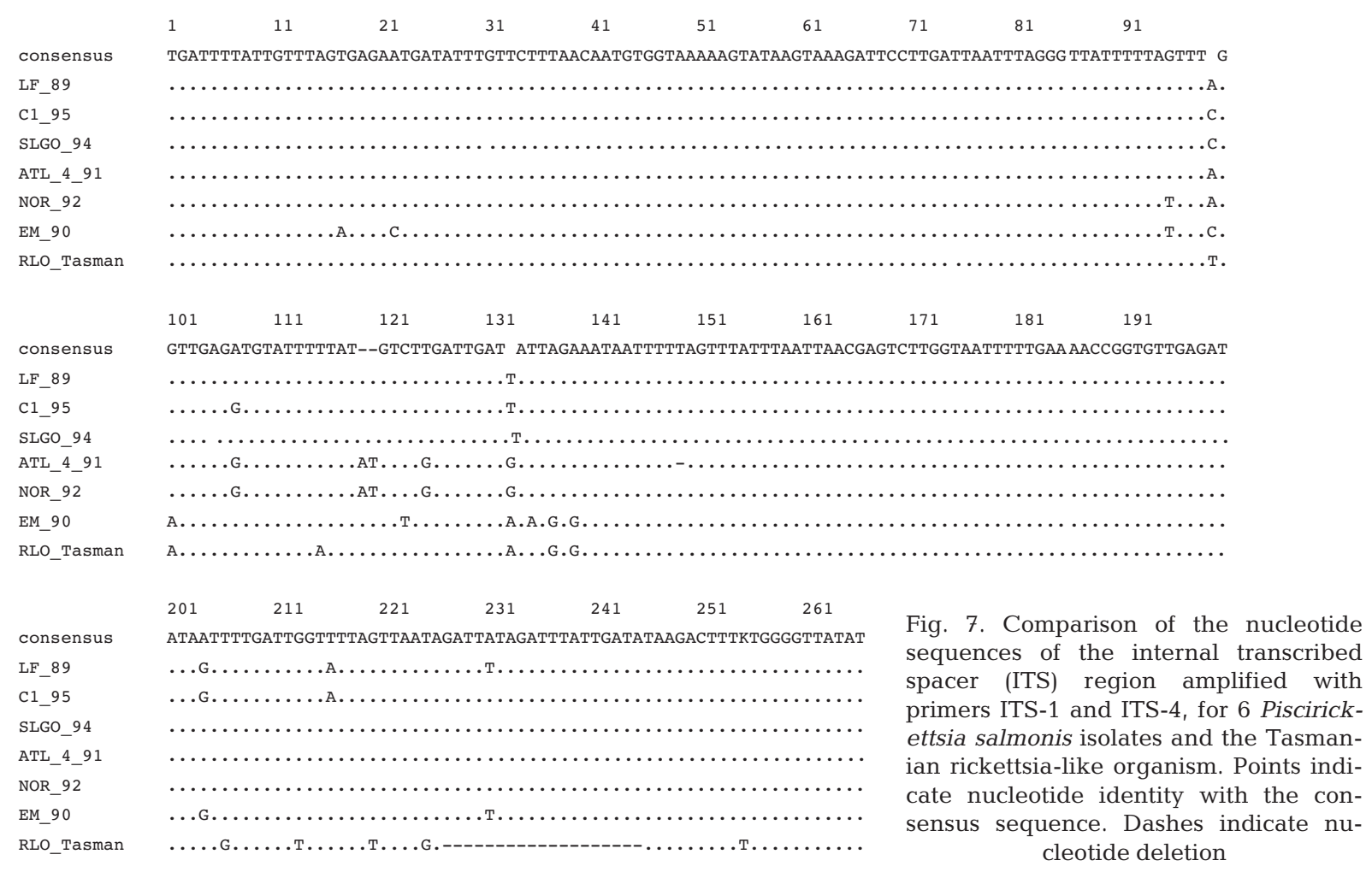




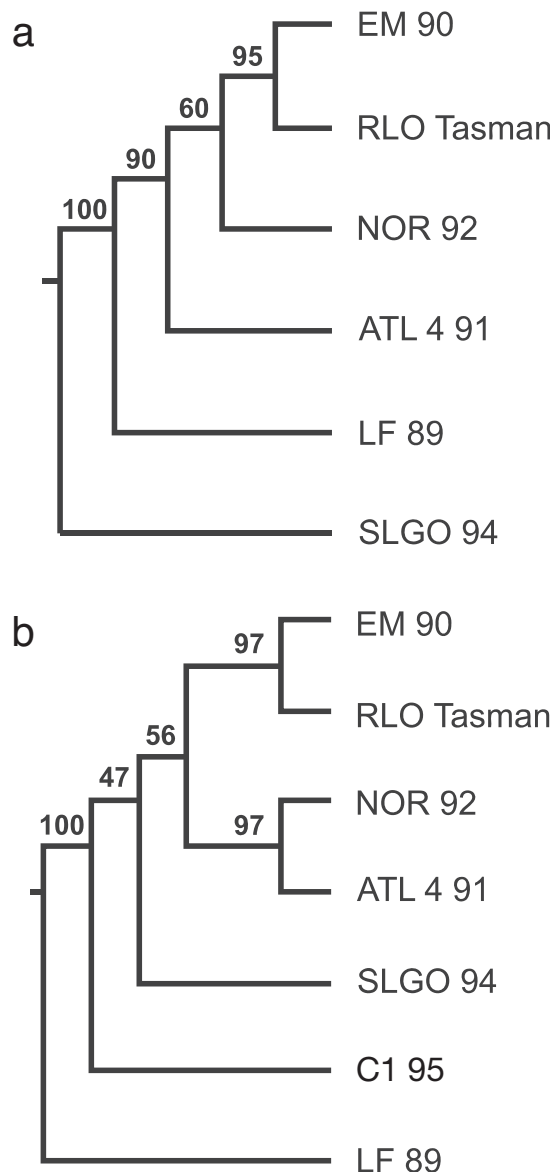

Fig. 8. Phylogenetic analysis of (a) 16S rRNA and (b) ITS rRNA sequences constructed using distance method (Jukes \& Cantor). Bootstrap support from 100 replicates shown at nodes

genic determinants between the RLO and P. salmonis. Even though only weak labelling was observed on the RLO infected tissues, no gold particles were observed on host cells or structures or on uninfected fish tissues (Fig. 6), indicating that the labelling was specific. Weak antigenic cross reactivity of the $P$. salmonis polyclonal antiserum with the Tasmanian RLO is a possible explanation for the low level staining. In a similar study involving the isolation of a white sea bass (Atractoscion nobilis) RLO, Chen et al. (2000a) reported that a $P$. salmonis specific polyclonal antiserum also produced a weak cross-reaction with the white sea bass RLO. These data suggest the existence of RLOs that are not $P$. salmonis. Moreover, the inability to culture the Tasmanian RLO in vitro under the conditions employed in this study may suggest a further difference between this organism and $P$. salmonis isolates.

In order to characterise the Tasmanian RLO at the molecular level we targeted the 16S rRNA gene, which is now well-established as a standard genetic marker for the identification of species, genera and families of bacteria (Woese 1987, Amann et al. 1995). In addition, it has also been demonstrated that the ITS region of the rRNA operon is useful to differentiate species of prokaryotes (Barry et al. 1991, Jensen et al. 1993). A previous study based on the analysis of the rRNA operon of 5 isolates of Piscirickettsia salmonis suggested that sequence data from 3 regions (16S-ITS23S) provided similar phylogenetic information (Mauel et al. 1999). The 5 isolates under investigation were then found to be closely related to each other. However, the EM-90 Chilean isolate was described as unique, showing slightly lower percent sequence identity in its rRNA sequences. The authors concluded that this latter isolate had diverged genetically from the others. In our current study, a phylogenetic analysis performed on this partial gene sequence of the 16S rDNA indicated that the Tasmanian RLO is closely related to $P$. salmonis, and particularly to the Chilean isolate EM-90 (Fig. 8a). In addition, we chose to amplify and sequence the RTS-1/RTS-4 amplicon of the ITS region as it has been suggested as a promising region for monitoring genetic variation in P. salmonis (Marshall et al. 1998). This DNA region allowed us to further evaluate the genetic relatedness of the Tasmanian RLO with strains originating from other geographical regions. We found the ITS sequence of the Tasmanian RLO to be slightly less conserved than the 16S sequence when compared with the 5 exotic $P$. salmonis isolates (results not shown). The phylogenetic analysis performed on the ITS sequences also indicated that the Chilean isolate EM-90 found in Atlantic salmon is genetically the closest to the Tasmanian RLO (Fig. 8b). In order to further characterise the ITS region of the RLO, we performed a PCR amplification using the G1-L1 primer pair previously used by Casanova et al. (2001) with P. salmonis. Two tRNA sequences were also identified in the ITS region of the Tasmanian RLO. This genetic feature characteristic of $P$. salmonis isolates (Casanova et al. 2003) may be a basis to attribute the name of $P$. salmonis-like organism to the Tasmanian RLO.

The Tasmanian RLO shares morphological characteristics with Piscirickettsia salmonis (Fryer et al. 1990, Cvitanich et al. 1991, Rodger \& Drinan 1993) as well as with other RLOs (Chen et al. 2000b). While the 16S rDNA sequence and phylogenetic analysis demonstrated that the Tasmanian RLO is related to exotic $P$. salmonis isolates (Fig. 8a), the Tasmanian RLO exhibits an ITS sequence divergence with the $5 P$. salmonis isolates that were examined, principally due to a $19 \mathrm{bp}$ deletion (Fig. 7), which suggests a genetic divergence from $P$. salmonis. Sequence analysis of the rDNA ITS region of different strains of Escherichia coli has shown that large variations are found at certain locations in 
the ITS without apparent functional consequences (Anton et al. 1998) and this is probably also true among other members of Rickettsiales (Andersson et al. 1999). Certainly, compared with $P$. salmonis, the 19 bp deletion observed in the ITS region of the Tasmanian RLO has had no obvious effect on its pathogenic status in fish. Nonetheless, the relatively weak cross-reactivity of the Tasmanian RLO with P. salmonis-specific antiserum suggests that although the Tasmanian RLO is related to $P$. salmonis found in other countries there may be genetic variation elsewhere in the genome that has affected the nature of at least some antigenic determinants.

Recently, a Piscirickettsia-like organism, causing disease in Hawaiian tilapia, was found to have many morphological and pathogenic characteristics in common with $P$. salmonis. However, this organism did not produce an amplicon when a P. salmonis-specific PCR was performed (Mauel et al. 2003). Furthermore, other RLOs have been reported worldwide in different fish species (Khoo et al. 1995, Chen et al. 2000a,b). These cases emphasise the diversity of RLOs existing in aquatic species as well as the current inadequacy in the classification of aquatic rickettsia. Gene sequences from RLOs found in other fish species around the world will undoubtedly help to shed some light on the existing diversity of RLOs and help establish an appropriate classification of these emerging aquatic pathogens as it is not yet clear how similar a RLO would need to be in order to be classified $P$. salmonis.

The origin of this Tasmanian RLO is unknown; however, recent development of Atlantic salmon farms along the coast of Tasmania could have provided a new ecological niche for the RLO that may be endemic in wild indigenous species.

Acknowledgements. This study was partly funded by Fisheries Research and Development Corporation (project number: 2001/624). The authors thank Dr. M. House (Northwest Indian Fisheries Commission, USA) and Dr. J. Winton (USGS, Western Fisheries Research Center, USA) for kindly providing paraffin blocks of Piscirickettsia salmonis-infected fish tissues used in this study. Thanks also to Mr. T. Pye for the sequencing work, Ms. S. Crameri for the electron microscope work, Ms. N. Williams and Mr. J. Young for the cell culture work and to Mr. N. Gudkovs for providing bacterial DNA and for comments on bacterial rDNA operons (CSIRO Livestock Industries, Australia). Thanks to Dr. L. Wang and Mr. I. Pritchard for reviewing the manuscript and Ms. D. Jackson for editing the manuscript (CSIRO Livestock Industries, Australia).

\section{LITERATURE CITED}

Amann RI, Ludwig W, Schleifer KH (1995) Phylogenetic identification and in situ detection of individual microbial cells without cultivation. Microbiol Rev 59:143-169
Andersson GE, Stothard DR, Fuerst P, Kurland CG (1999) Molecular phylogeny and rearrangement of rRNA genes in Rickettsia species. Mol Biol Evol 16:987-995

Anton AI, Martinez-Murcia AJ, Rodriguez-Valera F (1998) Sequence diversity in the $16 \mathrm{~S}-23 \mathrm{~S}$ intergenic spacer region (ISR) of the operons in representatives of the Escherichia coli ECOR collection. J Mol Evol 47:62-72

Barry T, Colleran G, Glennon M, Dunican LK, Gannon F (1991) The 16S/23S ribosomal spacer region as a target for DNA probes to identify eubacteria. PCR Meth Appl 1: $51-56$

Birrell J, Mitchell S, Bruno DW (2003) Piscirickettsia salmonis in farmed Atlantic salmon, Salmo salar in Scotland. Bull Eur Assoc Fish Pathol 23:213-218

Bravo S, Campos M (1989) Coho salmon syndrome in Chile. AFS/FHS Newsl 17:3

Casanova A, Obreque J, Sandino AM, Jashes M (2001) tRNA genes were found in Piscirickettsia salmonis 16S-23S rDNA spacer region (ITS). FEMS Microbiol Lett 197:19-22

Casanova A, Obreque J, Gaggero A, Landskron E, Sandino AM, Jashes M (2003) Electrophoretic analysis of ITS from Piscirickettsia salmonis Chilean isolates. FEMS Microbiol Lett 225:173-176

Chen MF, Yun S, Marty GD, McDowell TS and 5 others (2000a) A Piscirickettsia salmonis-like bacterium associated with mortality of white seabass Atractoscion nobilis. Dis Aquat Org 43:117-126

Chen SC, Wang PC, Tung MC, Thompson KD, Adams A (2000b) A Piscirickettsia salmonis-like organism in grouper, Epinephelus melanostigma, in Taiwan. J Fish Dis 23:415-418

Corbeil S, McColl K, Crane M (2003) Development of a TaqMan quantitative PCR assay for the identification of Piscirickettsia salmonis. Bull Eur Assoc Fish Pathol. 23:95-101

Cvitanich JD, Garate NO, Smith CE (1991) Isolation of a rickettsial-like organism causing diseases and mortality in Chilean salmonids and its confirmation by Koch's postulate. J Fish Dis 14:121-145

Evelyn TPT (1992) Salmonid rickettsial septicemia. In: Kent ML (ed) Diseases of seawater netpen-reared salmonid fishes in the Pacific northwest. Canadian Special Publication of Fisheries and Aquatic Sciences 116. Dept Fisheries and Oceans, Nanaimo, BC, p 18-19

Felsenstein J (1989) PHYLIP phylogeny inference package (Version 3.5). Cladistics 5:164-166

Fryer JL, Mauel MJ (1997) The rickettsia: an emerging group of pathogens in fish. Emerg Infect Dis 3:137-144

Fryer JL, Lannan CN, Garces LH, Larenas JJ, Smith PA (1990) Isolation of a rickettsiales-like organism from diseased coho salmon Oncorhynchus kisutch in Chile. Fish Pathol 25:107-114

Fryer JL, Lannan CN, Giovannoni SJ, Wood ND (1992) Piscirickettsia salmonis gen. nov., sp. nov., the causative agent of an epizootic disease in salmonid fishes. Int J Syst Bacteriol 42:120-126

Grant AN, Brown AG, Cox DI, Birkbeck TH, Griffen AA (1996) Rickettsia-like organism in farmed salmon. Vet Rec 138:423

Hyatt AD (1989) Protein A-gold: nonspecific binding and cross-contamination. In: Hayat MA (ed) Colloidal gold: principles, methods and applications, Vol 2. Academic Press, San Diego, CA, p 19-31

Hyatt AD (1991) Immunogold labelling techniques. In: Harris JR (ed) Electron microscopy in biology: a practical approach. IRL Press, Oxford, p 59-80

Jensen MA, Webster JA, Straus N (1993) Rapid identification of bacteria on the basis of polymerase chain reaction- 
amplified ribosomal DNA spacer polymorphisms. Appl Environ Microbiol 59:945-952

Jones SRM, Markham RJF, Groman DB, Cusack RR (1998) Virulence and antigenic characteristics of a cultured rickettsiales-like organism isolated from farmed Atlantic salmon Salmo salar in Eastern Canada. Dis Aquat Org 33: 25-31

Khoo L, Dennis PM, Lewbart GA (1995) Rickettsia-like organisms in the blue-eyed plecostomus, Panaque suttoni (Eigenmann \& Eigenmann). J Fish Dis 18:157-164

Marshall S, Heath S, Henriquez V, Orrego C (1998) Minimally invasive detection of Piscirickettsia salmonis in cultivated salmonids via the PCR. Appl Environ Microbiol 64: 3066-3069

Mauel MJ, Giovannoni SJ, Fryer JL (1996) Development of polymerase chain reaction assays for detection, identification, and differentiation of Piscirickettsia salmonis. Dis Aquat Org 26:189-195

Mauel MJ, Giovannoni SJ, Fryer JL (1999) Phylogenetic analysis of Piscirickettsia salmonis by $16 \mathrm{~S}$, internal tran-

Editorial responsibility: Carey Cunningham, Aberdeen, UK scribed spacer (ITS) and 23S ribosomal DNA sequencing. Dis Aquat Org 35:115-123

Mauel MJ, Miller DL, Frazier K, Liggett AD, Styer L, Montgomery-Brock D, Brock J (2003) Characterization of a piscirickettsiosis-like disease in Hawaiian tilapia. Dis Aquat Org 53:249-255

Olsen AB, Melby HP, Speilberb L, Evensen O, Hastein T (1997) Piscirickettsia salmonis infection in Atlantic salmon Salmo salar in Norway-epidemiological, pathological and microbiological findings. Dis Aquat Org 31:35-48

Rodger HD, Drinan EM (1993) Observation of a rickettsialeslike organism in Atlantic salmon, Salmo salar L., in Ireland. J Fish Dis 16:361-369

Thompson JD, Higgins DG, Gibson TJ (1994) CLUSTAL W: improving the sensitivity of progressive multiple sequence alignment through sequence weighting, position-specific gap penalties and weight matrix choice. Nucleic Acids Res 22:4673-4680

Woese CR (1987) Bacterial evolution. Microbiol Rev 51: 221-271

Submitted: April 1, 2004; Accepted: November 1, 2004 Proofs received from author: March 8, 2005 